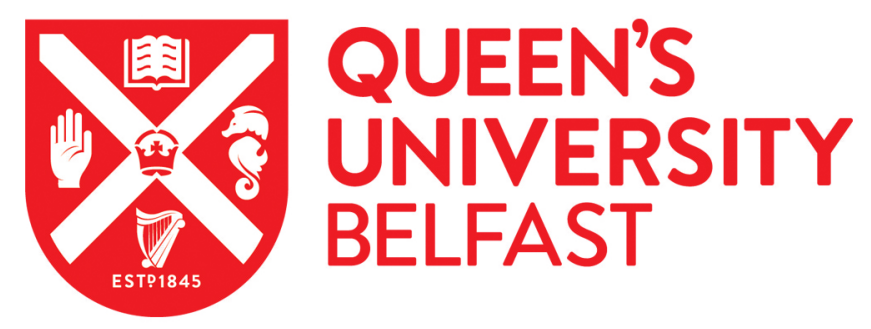

\title{
Evaluating laser-driven Bremsstrahlung radiation sources for imaging and analysis of nuclear waste packages
}

Jones, C. P., Brenner, C. M., Stitt, C. A., Armstrong, C., Rusby, D. R., Mirfayzi, S. R., Wilson, L. A., Alejo, A., Ahmed, H., Allott, R., Butler, N. M. H., Clarke, R. J., Haddock, D., Hernandez-Gomez, C., Higginson, A., Murphy, C., Notley, M., Paraskevoulakos, C., Jowsey, J., ... Scott, T. B. (2016). Evaluating laser-driven Bremsstrahlung radiation sources for imaging and analysis of nuclear waste packages. Journal of Hazardous Materials. https://doi.org/10.1016/j.jhazmat.2016.07.057

Published in:

Journal of Hazardous Materials

Document Version:

Peer reviewed version

Queen's University Belfast - Research Portal:

Link to publication record in Queen's University Belfast Research Portal

Publisher rights

(C) 2016 Elsevier Ltd. This manuscript version is made available under the CC-BY-NC-ND 4.0 license http://creativecommons.org/licenses/bync-nd/4.0/which permits distribution and reproduction for non-commercial purposes, provided the author and source are cited.

General rights

Copyright for the publications made accessible via the Queen's University Belfast Research Portal is retained by the author(s) and / or other copyright owners and it is a condition of accessing these publications that users recognise and abide by the legal requirements associated with these rights.

Take down policy

The Research Portal is Queen's institutional repository that provides access to Queen's research output. Every effort has been made to ensure that content in the Research Portal does not infringe any person's rights, or applicable UK laws. If you discover content in the Research Portal that you believe breaches copyright or violates any law, please contact openaccess@qub.ac.uk. 


\title{
Evaluating laser-driven bremsstrahlung radiation sources for imaging and analysis of nuclear waste packages
}

Christopher P. Jones*a, Ceri M. Brenner ${ }^{\mathrm{b}}$, Camilla A. Stitt ${ }^{\mathrm{a}}$, Chris Armstrong $^{\mathrm{b}, \mathrm{c}}$, Dean R. Rusby ${ }^{\mathrm{b}, \mathrm{c}}$, Seyed R. Mirfayzi ${ }^{\mathrm{d}}$, Lucy A. Wilson ${ }^{\mathrm{b}}$, Aarón Alejo ${ }^{\mathrm{d}}$, Hamad Ahmed ${ }^{\mathrm{d}}$, Ric Allott ${ }^{\mathrm{b}}$, Nicholas M. H. Butler ${ }^{\mathrm{c}}$, Robert

J. Clarke ${ }^{\mathrm{b}}$, David Haddock ${ }^{\mathrm{b}}$, Cristina Hernandez-Gomez ${ }^{\mathrm{b}}$, Adam

Higginson $^{\mathrm{c}}$, Christopher Murphy ${ }^{\mathrm{e}}$, Margaret Notley ${ }^{\mathrm{b}}$, Charilaos

Paraskevoulakos $^{\mathrm{a}}$, John Jowsey ${ }^{\mathrm{f}}$, Paul McKenna ${ }^{\mathrm{c}}$, David Neely ${ }^{\mathrm{b}}$, Satya

Kard $^{\mathrm{d}}$, Thomas B. Scott ${ }^{\mathrm{a}}$

${ }^{a}$ Interface Analysis Centre, HH Wills Physics Laboratory, Tyndall Avenue, Bristol, BS8

1TL, UK * corresponding author: cj0810@bristol.ac.uk

${ }^{b}$ Central Laser Facility, STFC, Rutherford Appleton Laboratory, Didcot, Oxon, OX11 $O Q X, U K$

${ }^{c}$ Department of Physics, SUPA, University of Strathclyde, Glasgow G4 ONG, UK

${ }^{d}$ Centre for Plasma Physics, Queen's University Belfast, Belfast BT7 1NN, UK

${ }^{e}$ Department of Physics, University of York, York YO10 5DD, UK

${ }^{f}$ Ground Floor North B582, Sellafield Ltd, Seascale, Cumbria CA20 1PG

\begin{abstract}
A small scale sample nuclear waste package, consisting of a $28 \mathrm{~mm}$ diameter uranium penny encased in grout, was imaged by absorption contrast radiography using a single pulse exposure from an x-ray source driven by a highpower laser. The Vulcan laser was used to deliver a focused pulse of photons to a tantalum foil, in order to generate a bright burst of highly penetrating x-rays (with energy $>500 \mathrm{keV}$ ), with a source size of $<0.5 \mathrm{~mm}$. BAS-TR and BAS-SR image plates were used for image capture, alongside a newly developed Thalium doped Caesium Iodide scintillator-based detector coupled to CCD chips. The uranium penny was clearly resolved to sub-mm accuracy over a $30 \mathrm{~cm}^{2}$ scan area from a single shot acquisition. In addition, neutron generation was demonstrated in situ with the x-ray beam, with a single shot, thus demonstrating the potential for multi-modal criticality testing of waste materials. This feasibility study successfully demonstrated non-destructive radiography of encapsulated, high density, nuclear material. With recent
\end{abstract}


developments of high-power laser systems, to $10 \mathrm{~Hz}$ operation, a laser-driven multi-modal beamline for waste monitoring applications is envisioned.

Keywords: laser, x-ray, radiography, corrosion, nuclear

\section{Introduction}

\subsection{Background}

The majority of the UK's nuclear waste is currently stored at Sellafield in Cumbria, where a number of different storage strategies are applied depending on the type and radioactivity of each waste form. Also present are legacy nuclear waste storage facilities, which have contained waste materials for extended periods in a poorly controlled state. Urgent action is needed in some cases, e.g. the Magnox Swarf Storage Silo (MSSS), which requires extraction of the existing intermediate level waste (ILW) material from current storage, followed by processing and packaging in order to transform the material into a safer state, with both effective monitoring and environmental control. Due to the high radioactivity and unpredictable corrosion products exhibited by intermediate and high-level nuclear wastes, it is exceptionally difficult to accurately analyse simple parameters which describe the waste contents and therefore define the risks posed by particular storage scenarios. This is due to either the opacity of the physical containments or an inaccessibility to the waste, even for some well managed and controlled storages. The aforementioned parameters include the morphology, radioactivity, reactivity and chemical composition of the material, and any associated hazards such as gaseous hydrogen production.

For example, ILW arising from the processing of spent fuel from Magnox reactors consists of 500L stainless steel drums in-filled with Magnox cladding, aluminium, uranium and steel, encapsulated in a grout mixture of Ordinary Portland Cement and Blast Furnace Slag. Although originally designed to last for 'at least 50 years' $[1,2]$, recent inspections have shown that after $\sim 30$ years in storage, a small portion of the containers are beginning to exhibit signs of deformation as a result of metallic corrosion of the encapsulated ILW. Management of these particular containers is thwarted by the inability to identify the exact cause of the deformation and therefore validate their suitability for future interim storage ( $\leq 150$ years) without repackaging. In addition, deformation of the packaging, due to the volume expansion via metallic corrosion, greatly increases the chances of a localised 
containment breach. This is most likely during transportation, which carries with it the associated risk of an impact event. Similar storage environments have shown that the potential production of pyrophoric material is a recognised risk within these containers $[3,4]$. The legacy wastes at Sellafield site present further examples where limited material identification has hindered the processing of waste and its subsequent storage.

As the time for preparing a geological disposal facility draws closer, there is a requirement to accurately characterise and evaluate the stability and suitability of current nuclear waste packaging, repackaging and storage methods for the safe future storage, transportation and eventual disposal of waste. Currently, there are two approaches for accomplishing this: (1) direct investigation of the waste and (2) analytical studies of simulated waste to determine predictive corrosion rates and mechanisms occurring.

This investigation evaluates the capability of using the Vulcan laser at the STFC Central Laser Facility to demonstrate the potential for using laser-driven x-ray beams as a future means of examining the internal state of radioactive waste containers. Depending on the target composition, the photon-matter interaction produces either a bright pulse of highly penetrating x-rays for radiographic imaging or a pulse of neutrons. The x-rays can be generated with sufficient energy $(\sim 500 \mathrm{keV})$ to penetrate real world samples such as 500L waste drums providing a method of identifying corrosion products formed within. By switching target materials, a burst of neutrons will interact with the fissile material present in the sample. An analysis of the secondary neutrons produced will, potentially, generate a quantitative analysis of the isotopic composition of fissile material within the sample thereby performing criticality testing of the waste.

The current study was a successful feasibility experiment which produced radiographic data of simulated Magnox ILW waste material, with single pulse exposure from the laser-driven source. With recent developments of highpower laser systems, to $10 \mathrm{~Hz}$ operation with the energy levels required for gamma-ray production, a laser-driven multi-modal beamline for waste monitoring applications is envisioned. Improvements and modifications required for producing a stand-alone waste monitoring facility for Sellafield and other similar nuclear facilities are also discussed.

\subsection{Current monitoring methods}

At present, direct analysis of the waste includes conventional radiation detection and visual or video monitoring over long periods of time to detect 
external changes in the system. These methods do not have the capability of characterising the waste morphology or chemistry and are, therefore, incapable of identifying potential risks within the waste form. Additionally, some studies have proceeded to simulate waste environments either computationally, or in the laboratory, in order to predict specific metal behaviour, or the long term stability and integrity of the waste package systems. Finite element modelling has become a useful tool for understanding the mechanical behaviour of waste containers with progressive corrosion of metallic wastes held within. For example, Kallgren et al. investigated how material flow and heat affects the formation and distribution of cracks and voids during friction stir welding used to seal copper radwaste canisters [5]. However, successful predictive models require parameters derived from practical experimentation[6, 7]. In particular Wellman et al., [8] highlighted the need for a greater number of in-situ studies of metals retained in grout media. This is due to the fact that grout is a chemically and physically evolving system with solubility limiting metal-mineral phases, metal mobility, corrosion phases and mineral components all changing over time. For example, the presence of quartz $\left(\mathrm{SiO}_{2}\right)$, a primary component of grout, was neglected in grout behaviour studies by Glasser [9] and Atkins [10], when studying the $\mathrm{Ca}-\mathrm{UO}_{3}-\mathrm{H}_{2} \mathrm{O}$ system, even though valuable data was collected regarding the formation of sodium, calcium and uranium mineral phases. The main issue with creating analogous in-situ corrosion experiments is the required time frame to mimic current waste forms which have been evolving for up to 60 years. Consequently, the only accurate way of characterising a waste form is to perform a destructive physical examination which, in the case of radioactive waste packages, is far from trivial. Owing to the potential masses of pyrophoric and radioactive material that would be exposed to oxygen and the environment, this option is clearly not permissible. This leaves only one solution: determining a method of looking through the waste package, with good spatial resolution, and creating a computed tomography (CT) scan of the waste container.

Muon tomography can partially achieve this and utilises penetrating natural cosmic rays to produce $3 \mathrm{D}$ reconstructions of opaque objects via attenuation of the flux or coulombic scattering of particles from a single point $[11,12,13]$. Muon tomography is non-destructive, is sensitive to the materials atomic number and produces high Z-number contrast images. However, at the current technological status the resolution is poor, $2-12 \mathrm{~cm}$ per pixel (corrosion products form on the micrometre scale), scan times are long (hours to 
months) and it can only comparatively identify elements by their Z-number [11]. Furthermore, since muons are naturally occurring, there is no control over the muon flux, which limits development of the technique, particularly if larger, more complex, objects require analysis. Nevertheless, it is expected that these technologies will undergo a rapid change in the next few years and demonstrate good applicability for homeland security and for large scale scanning application where fine resolution is not required.

As an alternative approach to more accurately identify the waste chemistry and arising hazardous corrosion products, recent investigations have explored the use of synchrotron x-rays[14] capable of analysis at micron length scales. Synchrotron x-ray powder diffraction and tomographic analysis were used to explore the rate and mechanisms of metal corrosion, successfully characterising the developing morphology of the arising corrosion products and residual metal to a $1 \mu \mathrm{m}$ per pixel resolution. Important corrosion characteristics of uranium metal were determined using this method, for example, formation of $\mathrm{UH}_{3}$ on uranium encapsulated in grout was observed to initiate and propagate in large, protruding, blisters instead of forming a continuous layer across the metal surface (which is the typical case with unenclosed uranium metal). Furthermore, it was shown that these blisters persisted whilst submersed in water for at least 10 months $[14,15]$. However, due to uranium's high density $\left(18.95 \mathrm{~g} . \mathrm{cm}^{-3}\right)$, the x-ray attenuation was too great to analyse samples thicker than $1 \mathrm{~mm}$, even utilising the highest beam energy achievable at the synchrotron $(130 \mathrm{keV})$. Therefore, synchrotron $\mathrm{x}$-rays are considered a useful tool for small scale detailed investigations of uranium behaviour and corrosion when encapsulated in grout, but is not suitable for the monitoring of real waste containers.

X-ray transmission, calculated from NIST database tables[16], indicate that, in order to image typical industrial waste barrels and identify uranium samples, high fluxes of 500-1000keV x-rays are required to achieve the greatest image contrast. For example, $500 \mathrm{keV}$ x-rays travelling through a section of the barrel containing $10 \mathrm{~mm}$ thick uranium is attenuated by two orders of magnitude more compared to transmission through grout and steel alone. While x-rays with an energy of $2.5 \mathrm{MeV}$ x-ray are attenuated by only a factor of 2 in the same comparison. Therefore, broadband Maxwellian distribution x-ray spectra, peaked in the $0.5-1 \mathrm{MeV}$ region, are well suited for this imaging application. For x-rays with lower energy than this the transmission contrast is technically even greater (reaching $10^{16}$ for $100 \mathrm{keV}$ x-rays), however, the exceedingly low chance $\left(10^{-15}\right)$ of transmission makes this unob- 
tainable. Commercially available accelerator-based technology (e.g. linacs) generate this required x-ray spectral output, with the highest dose delivery reaching $20-100 \mathrm{~Gy} / \mathrm{min}$ at $1 \mathrm{~m}$ (peak on axis delivery) for premium line products from market leaders. However, the emission area (and therefore spatial resolution under projection radiography) is limited to $3 \mathrm{~mm}$. Estre et al provide a recent overview of high-energy x-ray radiography acquisition with newly developed detectors and advanced image construction techniques using a $9 \mathrm{MeV}$ linac[17]. High-power laser-matter interactions are also capable of generating x-ray beams with the ideal spectral output and have favourable beam and operational qualities for this imaging challenge. Namely, laserdriven sources can generate bright, ultra-short bursts (at 1m: 43mGy/pulse, $26 \mathrm{~Gy} / \mathrm{min}$ at $10 \mathrm{~Hz})[18]$ of high-energy $(>500 \mathrm{keV})$ x-rays from a small source area $(<0.5 \mathrm{~mm})$. Furthermore, the laser-driven concept also benefits from the option of generating an in situ, bright, short-pulsed, fast-neutron beamline ( $>1 \mathrm{MeV}$ neutron energy, $10^{8}$ neutrons/pulse), thus enabling a versatile multimodal probing system for the characterisation of nuclear waste containers.

\section{Experimental methods}

\subsection{Sample}

A natural uranium 'penny' with a diameter of $28 \mathrm{~mm}$ and thickness of $2 \mathrm{~mm}$ was cut from an unused, un-irradiated Magnox fuel rod (Figure 1(a)). The penny was encapsulated in Lafarge ready-mix concrete inside a plastic container (Figure 1(b)). The penny was not treated prior to encapsulation and, therefore, retained an as-received corrosion layer approximately $50-70 \mu \mathrm{m}$ thick and formed of uranium oxide $\left(\mathrm{UO}_{2}\right)$.

\subsection{X-ray generation}

When a laser pulse with a peak intensity greater than $10^{18} \mathrm{~W} / \mathrm{cm}^{2}$ is incident onto solid matter, the surface is instantaneously fully ionised to form a high density plasma. The laser electric field then interacts with the charged particles within the plasma state and accelerate a high-current (mega Ampere) of electrons in the laser forward direction. The generated electron beam has a Maxwellian spectral distribution and a bulk temperature up to several $\mathrm{MeV}$, rendering the beam relativistic. This beam in turn generates a bright burst of Bremsstrahlung x-ray radiation as the electrons interact with the atomic structure of the target material. The use of thin, high atomic number target foils (i.e. tantalum and gold) will result in a particularly 


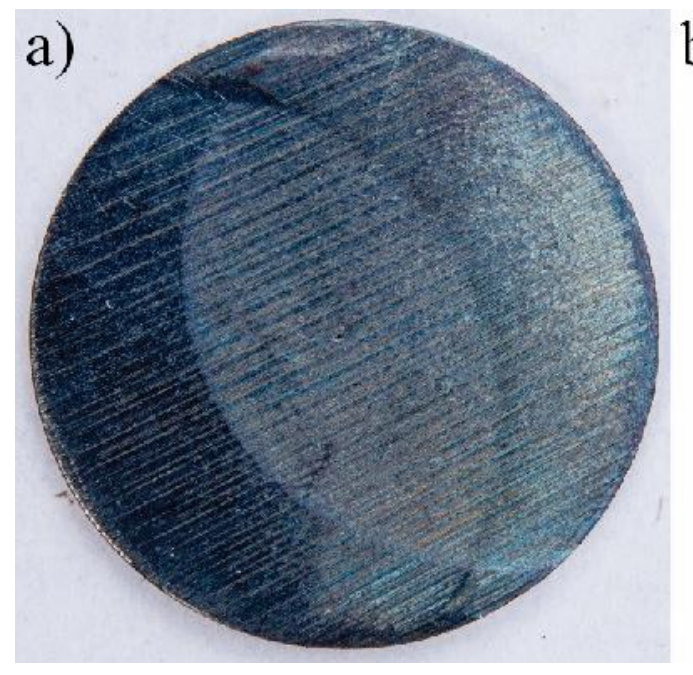

b)

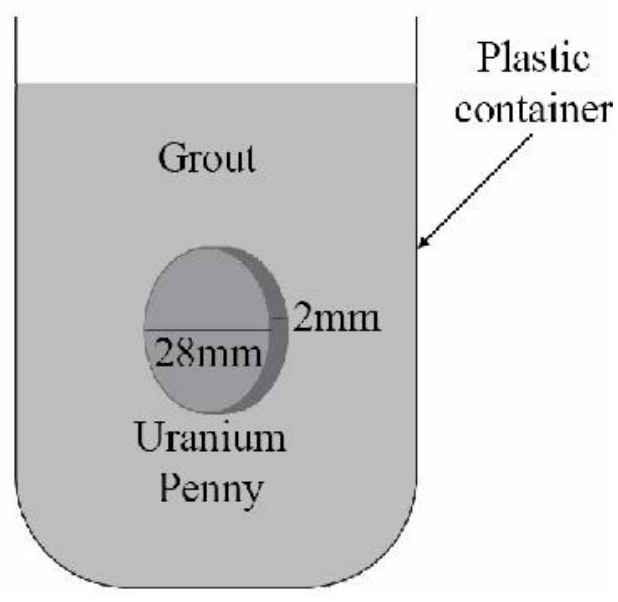

Figure 1: a) A photograph of the uranium metal penny. b) A schematic diagram of the entire sample.

high peak intensity and energy of Bremsstrahlung radiation, thus generating a large flux of high-energy x-rays. Dose measurements made during gold target irradiation with the Vulcan laser, at the Science and Technology Facilities Councils Rutherford Appleton Laboratory, show a total beam dose of $43 \mathrm{mGy} /$ pulse at $1 \mathrm{~m}[18]$. Finally, a review by Giuletti and Gizzi[19] provides a detailed introduction to x-ray emission from laser produced plasmas.

\subsection{Experimental setup}

Radiography was carried out utilising x-ray pulses generated during lasersolid interactions with the Vulcan laser at the Rutherford Appleton Laboratory, Harwell Campus. P-polarised, 1054nm wavelength pulses[20] of 10 picoseconds duration delivered $\sim 150 \mathrm{~J}$ of laser energy onto $100 \mu \mathrm{m}$ thick tantalum foil targets at a 20 degrees angle of incidence. In the current set-up, the Bremsstrahlung energy spectrum peaked at $200 \mathrm{keV}$, above which the photon flux logarithmically decreased. During imaging, spectrometer measurements indicated an x-ray beam with a bulk temperature of $\sim 600 \mathrm{keV}[21]$. A model of this distribution using GEANT4[22] was used to simulate a variety of input electron beam spectra transmitting through a $100 \mu \mathrm{m}$ tantalum foil (figure 2). Systematic variations in the incident laser energy are shown to directly correlate with the energy of the produced gamma rays[21]. This 
simulation demonstrated that gamma rays of $>2 \mathrm{MeV}$ were expected to be present during the current experiment.

BAS-TR and BAS-SR image plate (IP) detector films were used to capture the $\mathrm{x}$-rays after transmission through the sample in order to produce absorption contrast radiographs. A newly developed 2D active scintillatorbased detector, constructed of Thalium doped Caesium Iodide (CsI) pixels of dimensions $500 \times 500 \mu \mathrm{m}$ and a thickness of $1 \mathrm{~cm}$, optically coupled to CCD chips, with full working area of $30 \mathrm{~cm}^{2}$, was also fielded. This active detector provided rapid, near instantaneous, image acquisition when compared to the traditional IP film, for which digitising the signal at high resolution can take up to an hour for a single $20 \mathrm{~cm} \times 40 \mathrm{~cm}$ piece. A $1.6 \mathrm{~cm}$ thick copper filter was positioned in front of the the scintillator array, attenuating x-rays of energy below $110 \mathrm{keV}$, in order to energy-select the irradiation onto the scintillator array (figure 2). The IP was left unfiltered so as to absorb all x-rays penetrating through the test objects, although, the IP has a peak sensitivity to x-rays with energy $\sim 50 \mathrm{keV}$ and is weakly attenuating for those $>100 \mathrm{keV}$. An aluminium filter was also trialled to filter out energies below $40 \mathrm{keV}$ but this was not seen to improve the quality of the collected data. The sample itself was positioned outside of the vacuum interaction chamber, level with the laser axis, at various distances in front of the detector plate in order to enable imaging at a range of magnification factors (Figure 3). Contact radiography (magnification 1 ) of the test object was conducted with the IP detector placed directly behind the object plane whilst high magnification (greater than a factor of 5) was carried out by extending the distance between the object and the CsI detector plane to 2.2 metres. 


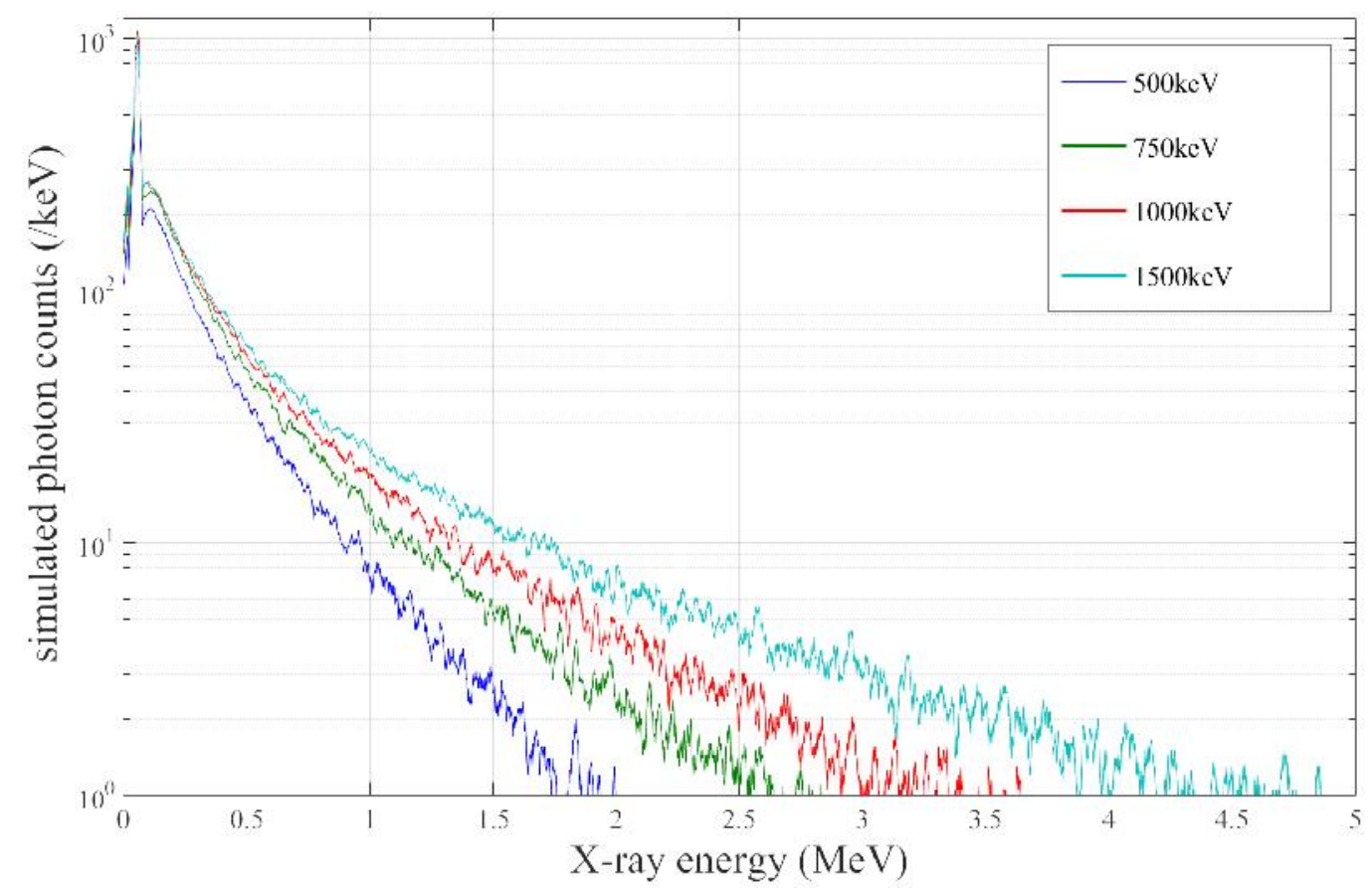

Figure 2: Generated x-ray spectra using the code GEANT4 to simulate a variety of input electron beam spectra travelling through a $100 \mu \mathrm{m}$ thick tantalum foil. The electron beam temperature input of the Maxwellian distributions range from $500 \mathrm{keV}$ (blue) to $1500 \mathrm{keV}$ (cyan). 


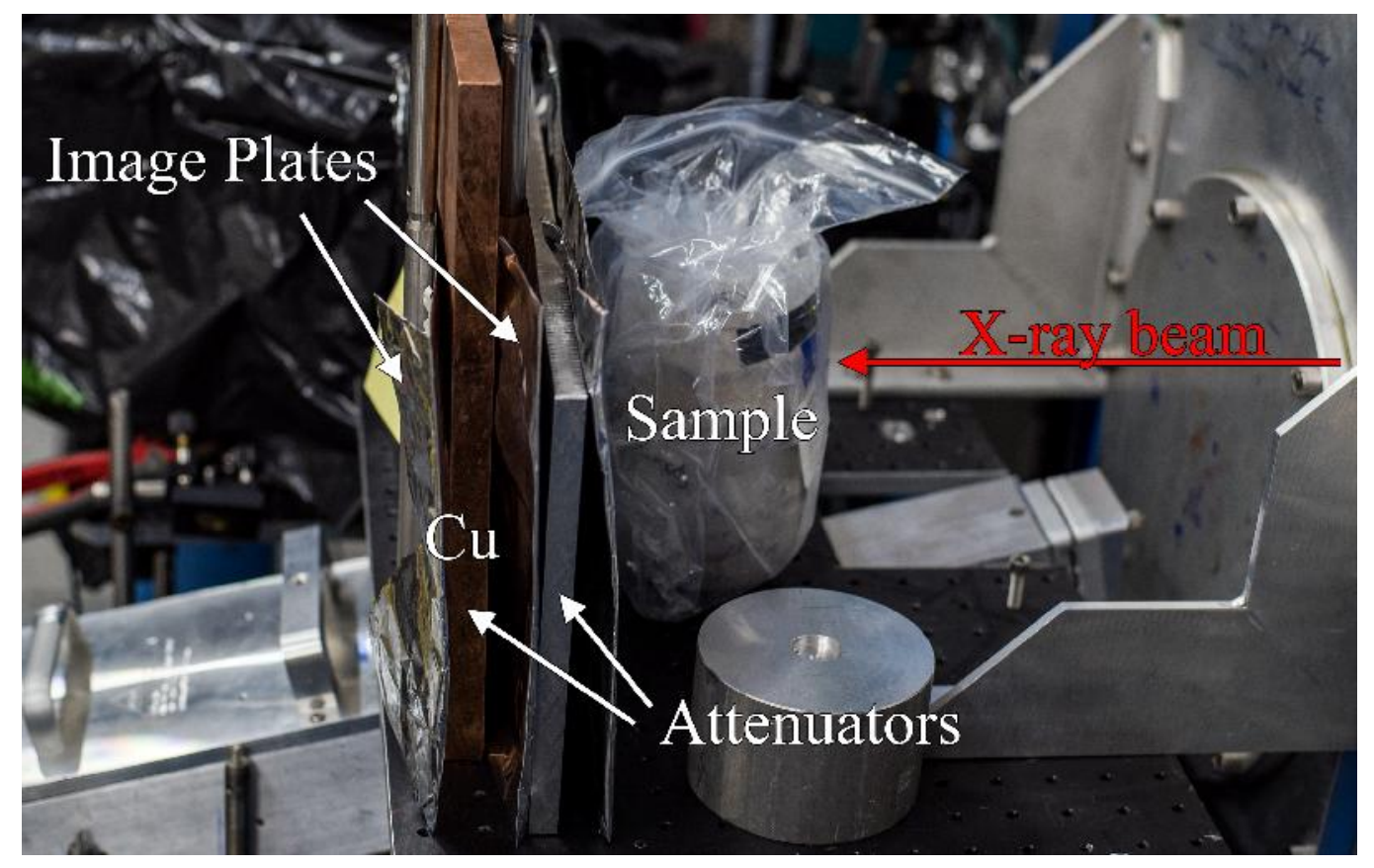

Figure 3: A photograph of the experimental set up, showing the position of the sample, image plates and filters with respect to the x-ray beam. 


\section{Results}

Rudimentary image processing was applied to the radiographs of the cement encapsulated uranium, using the IP and CsI detectors, and are displayed in Figures 4,5 and 6. Using both detectors, the outline of the uranium penny was clearly resolved regardless of the cross sectional thickness and at both low and high magnification factors. The high magnification CsI detector radiographs achieved a lower contrast ratio since the photon density at the detector plane ( $>2 \mathrm{~m}$ from the source) is much lower and the $1.6 \mathrm{~cm}$ thick $\mathrm{Cu}$ attenuator absorbed a high proportion of the beam energy. In addition the surrounding grout was observed to be intact with no apparent fracturing. Note that this new detector design is far from optimised. With improvements to scintillator grid structure, optical output coupling and CCD cooling, the image contrast quality will significantly improve with each advancement.

In both examples, the spatial resolution and absorption contrast of the radiographs was insufficient to identify the $50-70 \mu \mathrm{m}$ thick, as-received, uranium oxide layer. Projection radiography, at a magnification factor of 5, onto the CsI array of a $5 \mathrm{~mm}$ thick tungsten resolution test grid demonstrated that features of size $200 \mu \mathrm{m}$ were resolved[21] indicating an x-ray source smaller than this. This experiment successfully demonstrated the first radiographic imaging of encapsulated uranium metal pennies using a single pulse exposure from a laser-driven x-ray beam.

In addition to x-rays, on a parallel beamline, a highly penetrating neutron beam (with an incident energy of $1-5 \mathrm{MeV}$ ) was generated [21]. A flux of $10^{7}-10^{9}$ neutrons per steradian per pulse were detected. Figure 7 shows the time-of-flight signal recorded by oscilloscopes from plastic scintillators positioned within the neutron path[23]. The saturated peak at time $t=0$ is a result of relativistic signal and, therefore, arises from the initial x-ray flash from bremsstrahlung emission. This is evidence for x-ray generation in the desired energy regime $(>500 \mathrm{keV})$, in situ and in line with neutron beam generation, since the scintillators were positioned two meters from the source and shielded by $10 \mathrm{~cm}$ thick lead bricks which could only be penetrated by such high-energy photons. An increase in signal between 100-200ns indicates radiation propagating at non-relativistic speeds but which has penetrated the lead shielding, thus indicating neutron irradiation. 


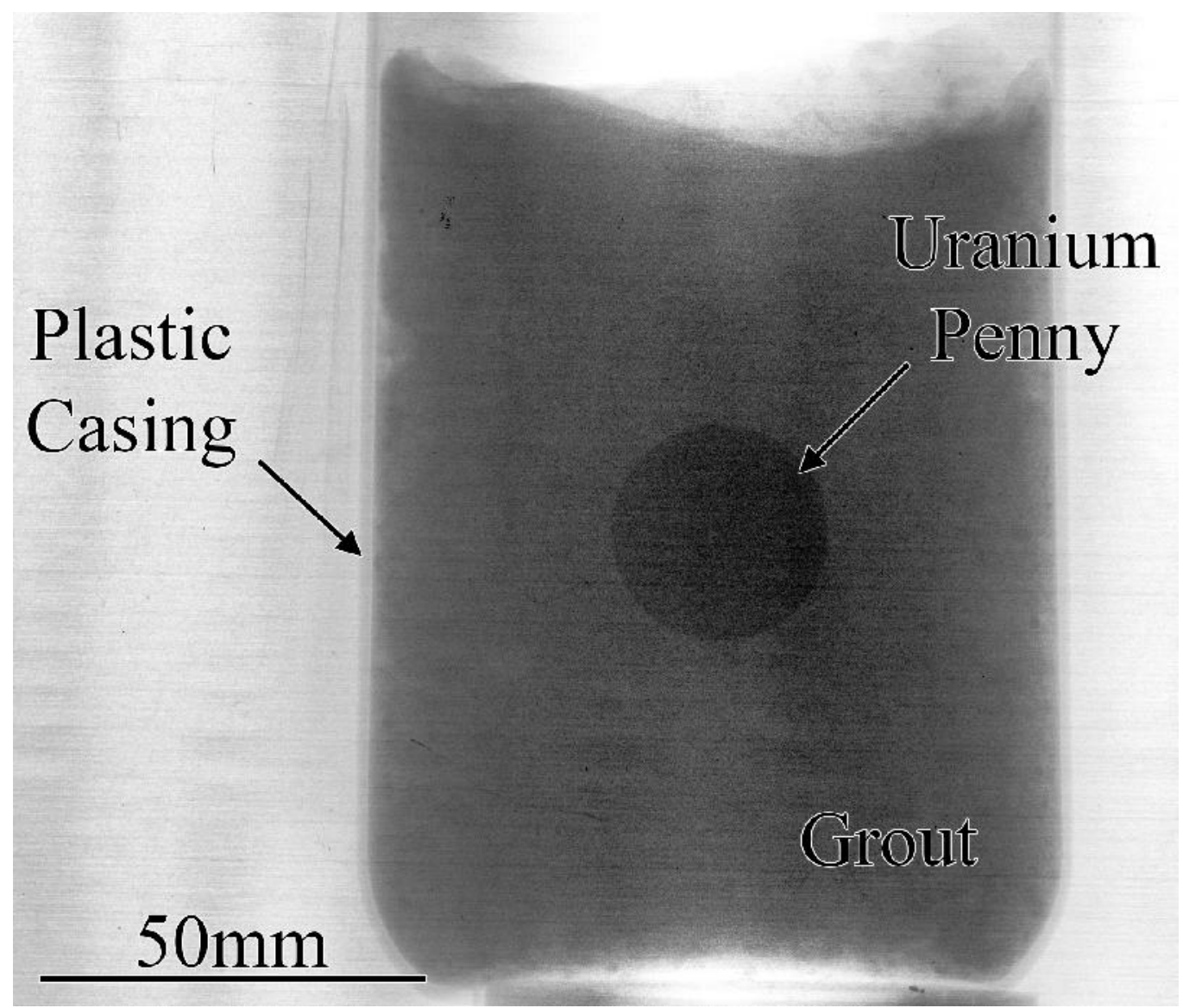

Figure 4: Raw signal from a single pulse exposure radiograph of the whole sample using no filters in front of an image plate detector (IP). The outline of the plastic container, cement and uranium penny are clearly shown. The high dynamic range of the image plate detector reveals absorption contrast even between materials of very different attenuation factor. 

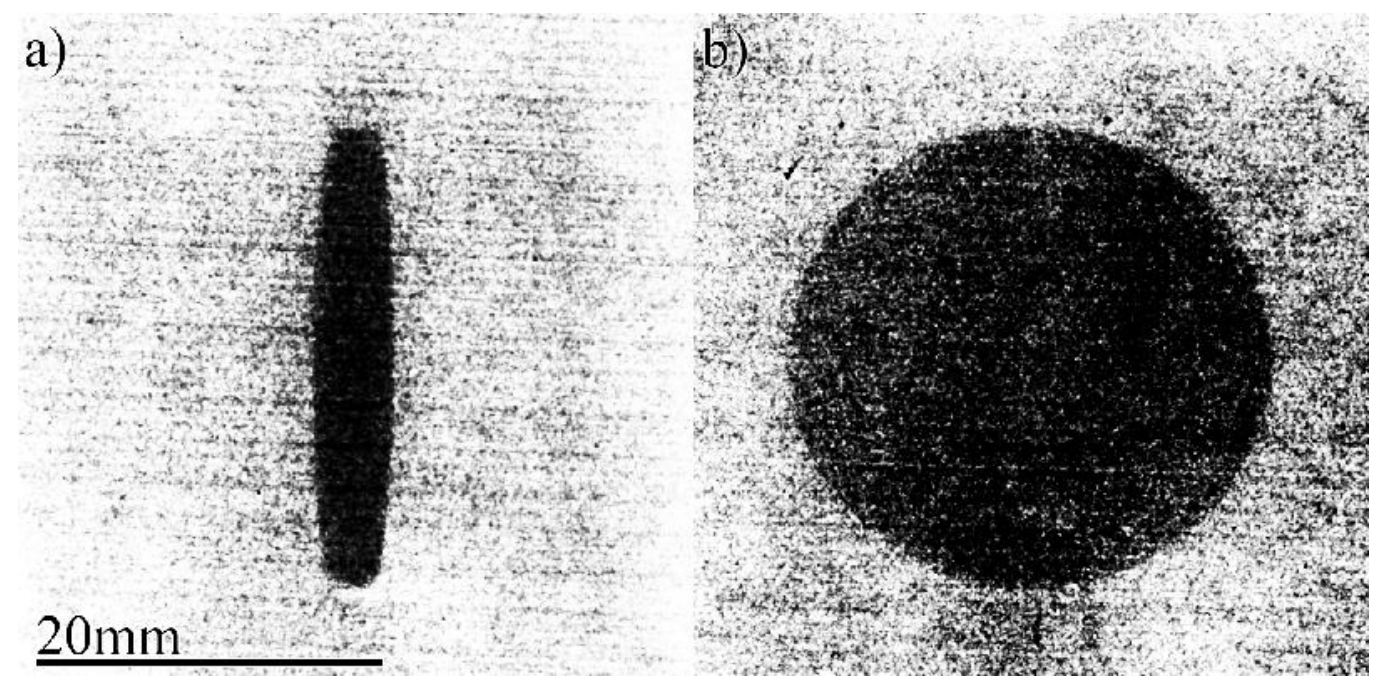

Figure 5: Contact radiography (magnification factor of 1) of the uranium penny through the thickest (a) and thinnest (b) orientations. These images were recorded using image plate films without filtering.

a) $2 \mathrm{~mm}$ cross-section

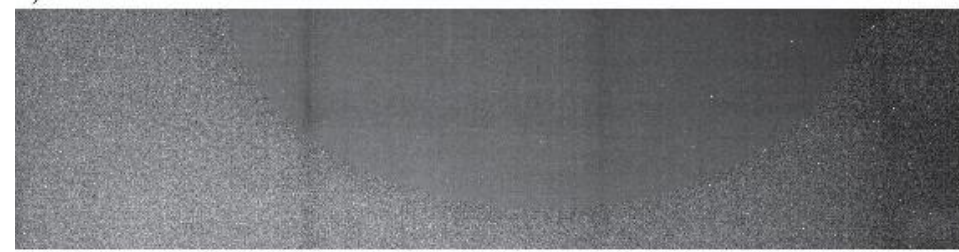

b) $2 m m$ cross-section

\section{c) $28 \mathrm{~mm}$ cross-section}

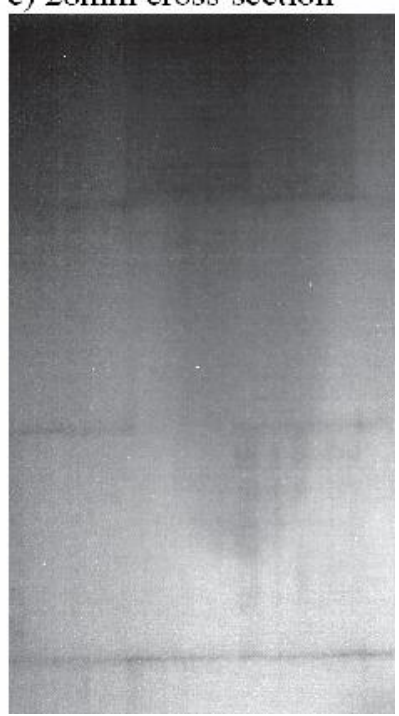

Figure 6: Projection radiography (magnification factor of $\sim 5$ ) of the uranium penny through the thinnest (a-b) and thickest (c) cross sections. These radiographs were recorded using the $\mathrm{CsI}$ detector with an additional $\mathrm{Cu}$ attenuator. The grid-like structure seen in the radiograph is an artefact from the tiled structure of the CsI array. 


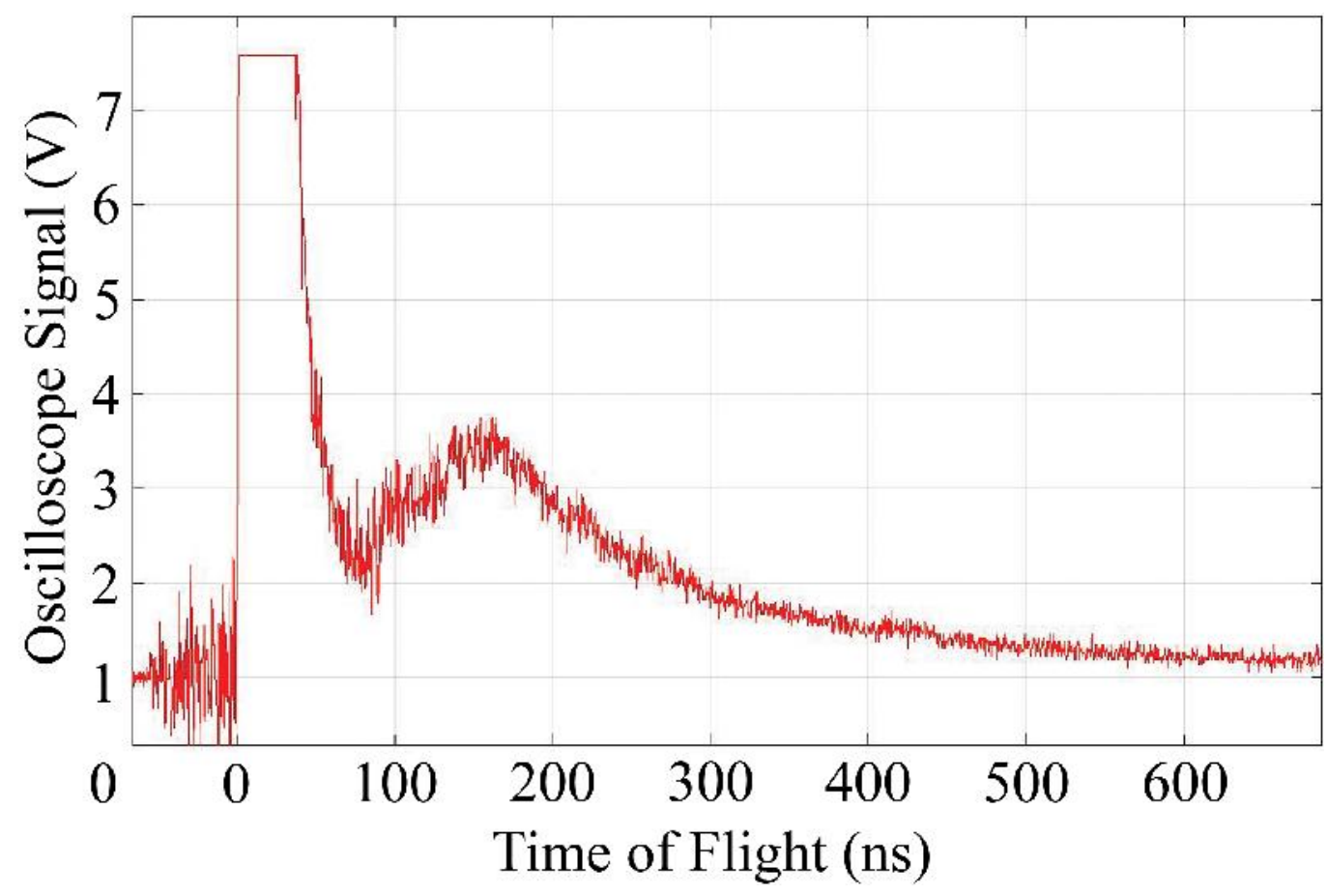

Figure 7: Raw neutron time-of-flight signal recorded by oscilloscopes during the experiment. 


\section{Discussion}

This feasibility study has successfully demonstrated non-destructive radiography of encapsulated high density nuclear material using the Vulcan laser system to drive high-energy x-ray beam generation. In the current configuration the laser pulse driven x-ray source was capable of penetrating medium masses of material, successfully achieving imaging spatial resolution down to $200 \mu \mathrm{m}[21]$ over wide scan areas of $\sim 30 \mathrm{~cm}^{2}$. Furthermore, this laser-based method of generating high-energy x-ray and particle beams exhibits potential for further development of additional techniques including x-ray tomography, gamma-ray tomography, neutron imaging and criticality testing.

\subsection{Advantages of a laser driven source}

Laser-driven, pulsed, x-ray sources have exhibited properties well suited for radiography and non-destructive testing applications in security and high value sectors, such as aerospace, nuclear, and advanced manufacturing[21]. The high resolution imaging of large, dense, objects is achievable due to the high-energy $(>500 \mathrm{keV})$, high-flux $(43 \mathrm{mGy})$ in each pulse, and the small size $(<0.5 \mathrm{~mm})$ of the source emission area. These characteristics are unique to laser driven sources when compared to their commercially available counterparts, such as linac systems, which cannot achieve all of these qualities in a single source. This tunable, laser-driven, system provides the flexibility to image a range of components and materials in a multitude of situations. It is, therefore, well suited to provide the advanced inspection techniques required in nuclear waste management, offering the potential for a ground-breaking analytical technique, of particular interest to the nuclear sector.

Other authors have previously conducted studies to characterise x-ray emission from high-power laser solid interactions across a variety of laser systems $[24,25]$, as well as radiography demonstration of the imaging qualities of the beams $[26,27,28]$. In the present experiment the x-ray beam demonstrated large divergence which permits a large field of view, thus providing a suitable foundation for the development of tomographic imaging of large objects. Simultaneous production of high-energy, bright neutron beams provides the potential for neutron radiography; a non-destructive, element specific, imaging technique, which is particularly sensitive to large variations in atomic number[29]. 


\subsection{Potential for nuclear waste scanning facility}

Adequate nuclear waste scanning requires the identification of the approximate mass and spatial distribution of i) high density material, ii) sensitive corrosion products, iii) fissile material, iv) pyrophoric material and v) any significant gas pockets or voids. This experiment has shown that laser-driven photon sources can successfully identify the distribution of material based on relative mass, from the stark difference between uranium and cements attenuation of the x-rays. Furthermore, real ILW containers often exhibit external deformation which is likely caused by expanding material located near the circumference. This is ascribed to volumetric expansion driven by corrosion of contained metal waste located close to the drum walls. The point source and divergent nature of the laser-driven photon beam should prove particularly capable at identifying this errant material since the transmission path through the drums margins is shorter than the centre of the container (Figure 8). Thus radiographs are expected to retain better absorption transmission contrast in these marginal areas with evidence of this observed in figure 4, which displays the entirety of the sample. Further experimentation is required to determine if additional low density corrosion products can also be identified using this method, however previous lower energy x-ray studies $(115 \mathrm{keV})$ have shown that this should be easily achievable[14].

Tuning the laser interaction to enhance and optimise the generation of high fluxes of x-rays in the $>500 \mathrm{keV}$ range is achieved by the combination of increasing the laser energy and shortening the pulse duration, thereby transferring the Bremsstrahlung energy profile peak further towards the $\mathrm{MeV}$ range. There are also alternative laser acceleration schemes that can generate high-energy x-ray beams. Laser wakefield acceleration sources focus a high-power laser into a gas capillary and utilise a bremsstrahlung converter foil to generate x-ray emission with very short pulse lengths of 30-40 fs and source size down to $\sim 30 \mu \mathrm{m}[30,31]$. The laser-accelerated electron energy in this case is tunable from several hundred $\mathrm{MeV}$ up to $\mathrm{GeV}$, generating average Bremsstrahlung radiation of $10-100$ 's $\mathrm{MeV}$ when the electron beam is passed through the converter foil[30, 26]. However, the beam emission is much more collimated and the photon density is greatly reduced, rendering large field-of-view single pulse exposure image acquisition infeasible. Currently, progression and development of imaging at this energy is limited by detector technology and instrumentation cooling. Detection of high-energy gamma rays requires development of a high density, high resolution, large 2D scintillator detector with rapid acquisition and processing times. Although 
acquisition of a single image yields rapid data acquisition (when using the CsI detector), current high-power laser technology limits multiple shot acquisition to $<1 \mathrm{~Hz}$ operation, since the systems work in 'flash-pump' mode and require up to several minutes to cool down between successive full power shots. This is overcome by using a high-power diode-pumped laser, such as the DiPOLE system[32], which not only offers high-power but can generate pulses at $10 \mathrm{~Hz}$ operation and is more efficient, more compact, and permits deployability. $10 \mathrm{~Hz}$ operation also leads to higher quality image processing via frame averaging. In addition, a rapid acquisition rate enables the development of a tomography system, which would provide accurate volumetric measurements of large mass systems containing both high and low density materials.

Materials posing the greatest risk to the safe confinement of nuclear waste are either hydrogen based, (e.g. hydrogen gas or metal hydrides) and, therefore, potentially flammable, or they are highly radioactive thus providing the potential for large accumulations of the material to reach criticality. Neutrons are highly sensitive to hydrogen based compounds, thus neutron imaging will be able to efficiently identify their location and relative quantity[33]. Neutrons have also previously been utilized for criticality testing, for example by the nuclear materials identification system (NMIS) [34]. In this method, a time resolved analysis is achieved; neutrons that pass through active material induces fission, generating additional particles that are detected later than directly transmitted neutrons. 
a)

2D Detector ILW container

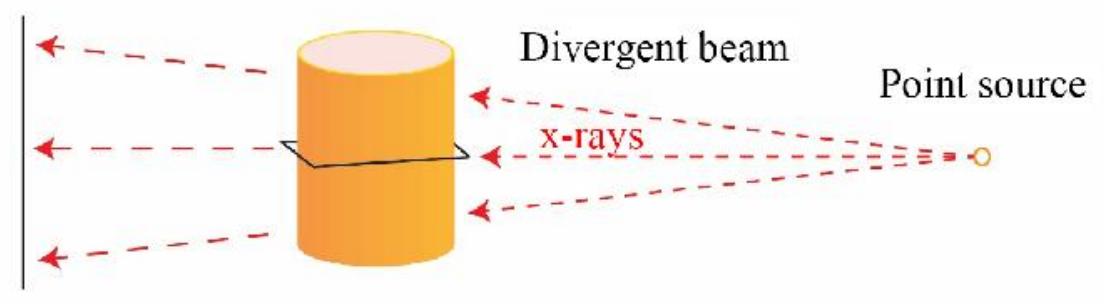

$\begin{array}{ll}\text { b) 2D Detcctor } & \text { D cross-section } \\ \text { of ILW container }\end{array}$

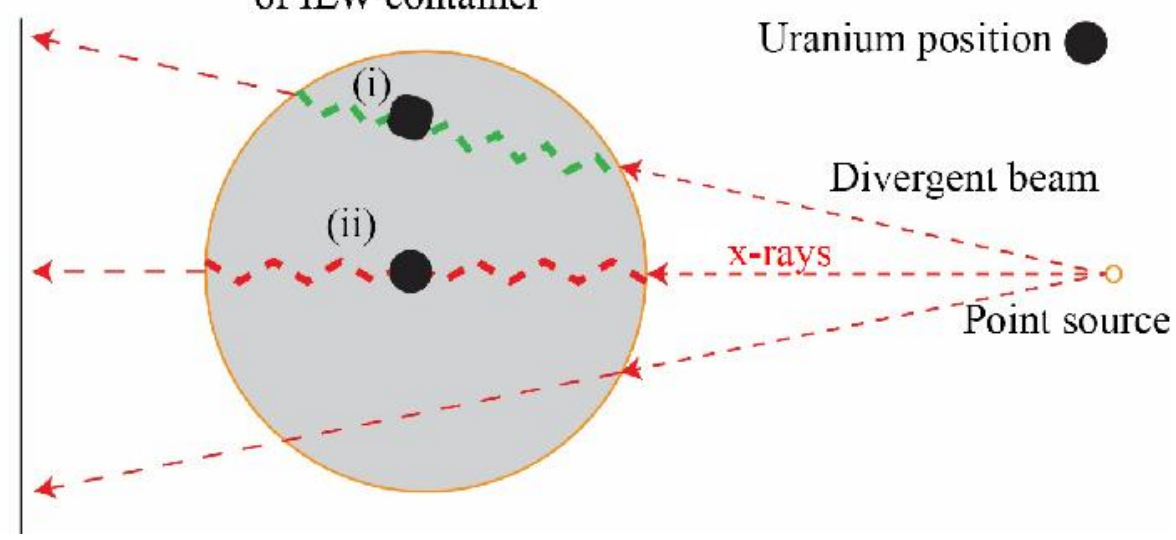

Figure 8: Schematic diagram demonstrating the advantages of a divergent beam from a point source for imaging of ILW containers. Deformation of ILW containers is often observed at the circumference of the container, where the gamma-ray transmission path is shorter (green), producing an image that has potentially higher contrast compared to the middle of the container where the path length is longer (red) and more likely to be scattered. 


\section{Conclusions}

This experiment has provided proof of concept for the development of laser induced gamma ray burst tomography and in-situ detection of high density materials in life-sized nuclear waste packages. By transitioning to the use of diode pumped lasers, multi-modal bursts of high-energy x-rays and neutrons will be achievable at rates of up to 10 images per second, allowing for both gamma-ray and neutron tomography. In addition, scaled up to $10 \mathrm{~Hz}$ operation, the dose delivery of a laser-driven x-ray beam is $26 \mathrm{~Gy} / \mathrm{min}$ at $1 \mathrm{~m}$, which is very competitive with even the highest energy market-leading linac systems.

The development and construction of this instrumentation is feasible on a 10 year timescale and holds potential for an in-situ waste scanning capability at nuclear waste storage facilities. Once operational, waste packages displaying errant behaviour will be prioritised for scanning and analysis, whilst standard packages will undergo routine product control and assessment before transportation to a geological disposal site.

\section{Future Work}

The work presented here was a feasibility study to determine the merits of more involved research and development as a step towards a commercial machine capable of $10 \mathrm{~Hz}$ operation. For real-world waste samples tomographic reconstruction will be required to identify corrosion products amongst the complex and random arrangement inside the canisters. This is attainable in a practical time-frame if multiple images per minute are acquired whilst the waste container is rotated. In addition, the x-ray energy needs to be high enough to penetrate the larger, dense, waste containers, therefore, further work is planned on the Vulcan system to image larger, more complex, samples as a second stage feasibility study. In addition neutron analysis is to be conducted in order to establish the accuracy of this method of quantifying the isotopic ratio of preconfigured samples (i.e. with known ratios of $\mathrm{U}^{235}$ to $\left.\mathrm{U}^{238}\right)$.

\section{Acknowledgements}

This research was supported by funding from Sellafield Ltd (CoE in uranium and reactive metals), with additional support from the Central Laser 
Facility and the STFC Business and Innovation Directorate for their funding of the access to the Vulcan laser facilities.

In addition, EPSRC grant number EP/J003832/1 and STFC grant number ST/K502340/1 were used in supporting work from Strathclyde university, and finally we would also like to thank the Royal Academy of Engineering for current and onwards support in developing this technology. 


\section{References}

[1] G. A. Fairhall, J. D. Palmer, Special double issue proceedings of symposium d of the e-mrs fall meeting 1991 the encapsulation of magnox swarf in cement in the united kingdom, Cement and Concrete Research 22 (2) (1992) 293-298. doi:http://dx.doi.org/10.1016/0008-8846(92)90068-7.

[2] J. D. Palmer, G. A. Fairhall, Special double issue proceedings of symposium d of the e-mrs fall meeting 1991 properties of cement systems containing intermediate level wastes, Cement and Concrete Research 22 (2) (1992) 325-330. doi:http://dx.doi.org/10.1016/0008-8846(92)90072-4.

[3] T. C. Totemeier, ., Characterization of uranium corrosion products involved in a uranium hydride pyrophoric event, Journal of Nuclear Materials 278 (23) (2000) 301-311. doi:http://dx.doi.org/10.1016/S0022$3115(99) 00245-7$.

[4] T. C. Totemeier, ., Report 0022-3115, Argonne National Laboratory (June 1995 1995).

[5] T. Kllgren, L.-Z. Jin, R. Sandstrm, Finite element modelling of temperature distribution in friction stir welding process and its influence on distortion of copper canisters, MRS Online Proceedings Library Archive 824 (2004) null-null. doi:doi:10.1557/PROC-824-CC1.14.

[6] H. J. Dagher, S. Kulendran, Finite element modeling of corrosion damage in concrete structures, Structural Journal 89 (6). doi:10.14359/4155.

[7] J. Padovan, J. Jae, Fe modeling of expansive oxide induced fracture of rebar reinforced concrete, Engineering Fracture Mechanics 56 (6) (1997) 797-812. doi:http://dx.doi.org/10.1016/S0013-7944(96)00132-4.

[8] D. M. Wellman, S. V. Mattigod, B. W. Arey, et al, Experimental limitations regarding the formation and characterization of uranium-mineral phases in concrete waste forms, Cement and Concrete Research 37 (2) (2007) 151. doi:http://dx.doi.org/10.1016/j.cemconres.2006.11.004.

[9] F. P. Glasser, A. A. Rahman, D. Macphee, et al, Immobilization of radioactive waste in cement-based matrices, Report, . (1985). 
[10] M. Atkins, F. P. Glasser, Application of portland cement-based materials to radioactive waste immobilization, Waste Management 12 (23) (1992) 105-131. doi:http://dx.doi.org/10.1016/0956-053X(92)90044-J.

[11] G. Jonkmans, V. N. P. Anghel, C. Jewett, et al, Nuclear waste imaging and spent fuel verification by muon tomography, Annals of Nuclear Energy 53 (2013) 267-273. doi:http://dx.doi.org/10.1016/j.anucene.2012.09.011.

[12] S. Pesente, S. Vanini, M. Benettoni, et al, First results on material identification and imaging with a large-volume muon tomography prototype, Nuclear Instruments and Methods in Physics Research Section A: Accelerators, Spectrometers, Detectors and Associated Equipment 604 (3) (2009) 738-746. doi:http://dx.doi.org/10.1016/j.nima.2009.03.017.

[13] K. N. Borozdin, G. E. Hogan, C. Morris, et al, Surveillance: Radiographic imaging with cosmic-ray muons, Nature 422 (6929) (2003) 277$277,10.1038 / 422277$ a.

[14] C. A. Stitt, M. Hart, N. J. Harker, et al, Nuclear waste viewed in a new light; a synchrotron study of uranium encapsulated in grout, Journal of Hazardous Materials 285 (2015) 221. doi:http://dx.doi.org/10.1016/j.jhazmat.2014.11.035.

[15] C. A. Stitt, N. J. Harker, K. R. Hallam, et al, An investigation on the persistence of uranium hydride during storage of simulant nuclear waste packages, PLoS ONE 10 (7) (2015) e0132284. doi:10.1371/journal.pone.0132284.

[16] M. Berger, J. Hubbell, S. Seltzer, et al, Xcom: Photon cross sections database. NIST Standard reference database (1998) 8:87.

[17] N. Estre, D. Eck, J. L. Pettier, et al, High-energy x-ray imaging applied to non destructive characterization of large nuclear waste drums, in: ANIMMA, 2013, p. 1. doi:10.1109/ANIMMA.2013.6727987.

[18] R. J. Clarke, D. Neely, R. D. Edwards, et al, Radiological characterisation of photon radiation from ultra-high-intensity laserplasma and nuclear interactions, Journal of Radiological Protection 26 (3) (2006) 277. 
[19] D. Giulietti, L. Gizzi, X-ray emission from laser-produced plasmas, La Rivista del Nuovo Cimento (1978-1999) 21 (10) (1998) 1-93. doi:10.1007/BF02874624.

[20] C. Hernandez-Gomez, P. Brummitt, D. Canny, et al, Vulcan petawattoperation and development, J. Phys. IV France 133 (2006) 555-559.

[21] C. M. Brenner, S. R. Mirfayzi, D. R. Rusby, et al, Laser-driven x-ray and neutron source development for industrial applications of plasma accelerators, Plasma Physics and Controlled Fusion 58 (1) (2016) 1.

[22] S. Agostinelli, J. Allison, K. Amako, et al, Geant4a simulation toolkit, Nuclear Instruments and Methods in Physics Research Section A: Accelerators, Spectrometers, Detectors and Associated Equipment 506 (3) (2003) 250-303. doi:http://dx.doi.org/10.1016/S0168-9002(03)01368-8.

[23] S. R. Mirfayzi, S. Kar, H. Ahmed, et al, Calibration of time of flight detectors using laser-driven neutron source, Review of Scientific Instruments $86 \quad$ (7) (2015) 073308. doi:doi:http://dx.doi.org/10.1063/1.4923088.

[24] C. D. Chen, A. J. Kemp, F. Prez, et al, Comparisons of angularly and spectrally resolved bremsstrahlung measurements to two-dimensional multi-stage simulations of short-pulse laserplasma interactions, Physics of Plasmas 20 (5) (2013) 052703. doi:doi:http://dx.doi.org/10.1063/1.4804348.

[25] R. D. Edwards, M. A. Sinclair, T. J. Goldsack, et al, Characterization of a gamma-ray source based on a laser-plasma accelerator with applications to radiography, Applied Physics Letters 80 (12) (2002) 2129. doi:doi:http://dx.doi.org/10.1063/1.1464221.

[26] Y. Glinec, J. Faure, L. L. Dain, et al, High-resolution $\gamma$-ray radiography produced by a laser-plasma driven electron source, Physical Review Letters 94 (2) (2005) 025003, pRL.

[27] C. Courtois, R. Edwards, A. Compant La Fontaine, et al, High-resolution multi-mev x-ray radiography using relativistic lasersolid interaction, Physics of Plasmas 18 (2) (2011) 023101. doi:doi:http://dx.doi.org/10.1063/1.3551738. 
[28] A. Compant La Fontaine, C. Courtois, E. Lefebvre, et al, Effects of electron recirculation on a hard x-ray source observed during the interaction of a high intensity laser pulse with thin au targets, Physics of Plasmas 20 (12) (2013) 123111. doi:doi:http://dx.doi.org/10.1063/1.4848759.

[29] M. Roth, D. Jung, K. Falk, et al, Bright laser-driven neutron source based on the relativistic transparency of solids, Physical Review Letters 110 (4) (2013) 044802, pRL.

[30] S. Cipiccia, S. M. Wiggins, R. P. Shanks, et al, A tuneable ultra-compact high-power, ultra-short pulsed, bright gamma-ray source based on bremsstrahlung radiation from laser-plasma accelerated electrons, Journal of Applied Physics 111 (6) (2012) 063302. doi:doi:http://dx.doi.org/10.1063/1.3693537.

[31] A. Ben-Ismal, O. Lundh, C. Rechatin, et al, Compact and high-quality gamma-ray source applied to 10 m-range resolution radiography, Applied Physics Letters 98 (26) (2011) 264101. doi:doi:http://dx.doi.org/10.1063/1.3604013.

[32] P. D. Mason, M. Fitton, A. Lintern, et al, Scalable design for a high energy cryogenic gas cooled diode pumped laser amplifier, Applied Optics 54 (13) (2015) 4227-4238. doi:10.1364/AO.54.004227.

[33] P. A. Hausladen, P. R. Bingham, J. S. Neal, et al, Portable fast-neutron radiography with the nuclear materials identification system for fissile material transfers, Nuclear Instruments and Methods in Physics Research Section B: Beam Interactions with Materials and Atoms 261 (12) (2007) 387-390. doi:http://dx.doi.org/10.1016/j.nimb.2007.04.206.

[34] J. T. Mihalczo, J. A. Mullens, J. K. Mattingly, et al, Physical description of nuclear materials identification system (nmis) signatures, Nuclear Instruments and Methods in Physics Research Section A: Accelerators, Spectrometers, Detectors and Associated Equipment 450 (23) (2000) 531-555. doi:http://dx.doi.org/10.1016/S0168-9002(00)00304-1. 